\title{
Sexuality after Hematopoietic Stem Cell Transplantation
}

\author{
Jean C. Yi, PhD ${ }^{1}$ and Karen L. Syrjala, $\mathbf{P h D}^{1,2,3}$ \\ 1 Biobehavioral Sciences, Clinical Research Division, Fred Hutchinson Cancer Research Center
}

2Department of Psychiatry and Behavioral Sciences, University of Washington

3Survivorship Program, Fred Hutchinson Cancer Research Center

\begin{abstract}
As survival rates for hematopoietic stem cell transplantation (HSCT) have grown in the past two decades with improved management of acute toxicities, ${ }^{1-2}$ attention to long term complications has become more salient to clinicians, researchers, and survivors themselves. Sexual dysfunction has been defined as one of the most common long term issues following HSCT. ${ }^{3-4}$ Prospective studies have described the extent and nature of sexual difficulties in this population, ${ }^{4-6}$ and have also documented elevated problem rates relative to healthy controls. ${ }^{3-4,7-8}$ The aims of this article are to review the state of knowledge about sexual dysfunction following HSCT, to examine issues related to sexual dysfunction, and to address strategies to treat these long term problems.
\end{abstract}

HSCT is a procedure designed primarily for hematologic malignancies such as leukemia and lymphoma, although some solid tumors and non-malignant diseases such as aplastic anemia are also treated with this aggressive treatment method. Prior to the transplant, to prepare the body to receive stem cells, the conditioning regimens always include chemotherapy, usually supralethal doses of an alkylating agent such as cyclophosphamide or busulfan, and often including total body irradiation (TBI) at a dose of $1200 \mathrm{cGy}$ or higher. This process lowers immune defenses so that stem cells from either marrow or peripheral blood, donated from oneself (autologous) or from another person (allogeneic) can be infused. If the transplant is allogeneic, survivors are at risk for chronic graft versus host disease (GVHD), where the donor immune cells identify the body as foreign and attack it. Chronic GVHD can manifest anywhere in the body and often involves the skin, liver, eyes, mouth, sinuses and gut. ${ }^{2}$ For women, vaginal mucosal tissues are particularly susceptible. Chronic GVHD is managed with the use of immunosuppressants that often include high dose corticosteroids along with a calcineurin inhibitor such as cyclosporine or other newer agents that suppress immune recovery and bring a host of potential additional complications.

Recent efforts to reduce the toxicities of HSCT have utilized very low dose chemotherapies and TBI in attempts to optimize a 'graft versus leukemia' effect. This increasingly widely used methodology for treating hematologic malignancies seems to spare gonadal function along with other organ systems, but risks for chronic GVHD remain.

The population of HSCT survivors who receive high dose treatment is usually well under the age of 50, and most often relatively healthy until their diagnosis. Since treatment is so arduous and potentially toxic, major comorbidities are exclusions for eligibility for transplant. Thus

(C) 2008, KL Syrjala, Fred Hutchinson Cancer Research Center, All rights reserved.

Correspondence to: Karen L. Syrjala PhD, Fred Hutchinson Cancer Research Center, 1100 Fairview Ave. N., D5-220, Seattle, WA 98109, phone: 206.667.4579, fax: 206.667.4356, E-mail: ksyrjala@ fhcrc.org.

Jean C. Yi, PhD, Senior Fellow, Fred Hutchinson Cancer Research Center

Karen L. Syrjala, PhD, Director, Survivorship Program, Director, Biobehavioral Sciences, Fred Hutchinson Cancer Research Center 
women are frequently premenopausal and many men and women report active sex lives until the start of cancer treatment. While some transplant recipients have had several cycles of treatment prior to HSCT, others may have had little exposure to previous chemotherapy effects. The dramatic changes brought by treatment can make sexual adjustments more challenging than those of older adults already experiencing adaptations to aging-related physiological changes. This context begins to explain some of the deficits seen even many years after treatment in these HSCT survivors.

\section{Medical Factors Contributing to Sexual Dysfunction}

Numerous components of medical treatment impact sexual function, including chemotherapy, TBI, medications for chronic GVHD, and the other treatments for symptoms or side effects that are commonly used in cancer patients, such as anti-depressants. Alkylating agents are particularly toxic to gonadal function and consequently nearly all HSCT recipients are infertile following treatment (although infertility is not guaranteed, leaving a level of uncertainty unless confirmed with fertility testing). TBI is also toxic to gonadal function and can contribute to genital tissue sensitivity, atrophy or scarring. These treatments impair the production of testosterone at least for the first year for males, and induce ovarian failure for most women. $9-13$

Effects are not solely gonadal. Treatments are known to permanently damage function of the hypothalamic-pituitary-gonadal axis. ${ }^{14-15}$ Luteinizing hormone (LH) is elevated in most female survivors and normal in most males. Follicle stimulating hormone is elevated in over $90 \%$ of females and most males. Most females have primary ovarian failure with consequent low endogenous estrogen levels, and vaginal tissue atrophy is a risk. Chronic GVHD may also contribute to vaginal introital stenosis and mucosal changes that contribute to dyspareunia, vaginal irritation, and increased sensitivity of genital tissues. ${ }^{16}$ Male sexual problems have been attributed to gonadal and cavernosal arterial insufficiency with resulting libido and erectile dysfunction. ${ }^{17-18}$ TBI or chronic GHVD may contribute to scarring or adhesions in the blood vessels of the penis. Chronic GVHD can also cause inflammation, rash and sensitivity in the skin of the penis. Most males recover Leydig cell function by one year, returning testosterone levels to within normal range. ${ }^{14-15}$ However, males with sexual problems have been noted to have testicular insufficiency and diminished libido or erectile dysfunction even when serum testosterone levels are within normal range. ${ }^{17-20}$ Thus they may require dynamic testing of pituitary-gonadal function or empirical testing of testosterone supplementation if levels are low-normal. Ideally male testosterone levels would be tested before beginning treatment as a baseline indicator of an individual's 'norm'.

The type and dose of chemotherapy are factors to consider when identifying potential effects of treatment. ${ }^{13,21}$ In some studies comparing chemotherapy alone to HSCT, those patients who have received only chemotherapy report less sexual dysfunction in all phases of the sexual response cycle. ${ }^{22}$ However, this differential effect has not been confirmed in other research. 23

High dose corticosteroids are a common component of chronic GVHD treatment and can continue for years. This treatment not only suppresses endogenous hypothalamic and adrenal hormones, but also has major impacts on physical features and body image, along with potential for emotional lability and depression. Over time it creates cushingoid features with weight and fat gain along with loss of muscle. Major joint problems are not uncommon and include avascular necrosis that can require joint replacement. With all of these changes, it is not surprising that feelings of attractiveness and sexual responsiveness suffer. For many survivors who experience this treatment and its effects, sexual activity is put on hold for years and can 
consequently be difficult to re-initiate without intervention. In this circumstance, a combination of medical and behavioral treatments may be needed. ${ }^{24}$

Chronic GVHD can impact sexual functioning for women through a number of symptoms and physiological changes. $5,22,25-26$ Vaginal dryness, irritation, pain, and bleeding can be due to chronic GVHD as well as to ovarian failure. ${ }^{27-28}$ At times, as GVHD diminishes in other parts of the body, medication doses may be lowered but then GVHD in the vaginal area develops after resolving in other organs. ${ }^{29}$ In a medical chart review of 11 patients with vaginal chronic GVHD, women had been on a regimen of systemic cyclosporine and hormone therapy yet still developed chronic GVHD in the vulva and vagina. ${ }^{28}$ Onset occurred on average 10 months post-transplant but some women developed GVHD of the vulva/vagina as much as two years after HSCT. The pattern of GVHD of the vulva/vagina was most similar to GVHD found in the skin. Although, the severity of GVHD of the vagina did not correlate with the severity of GVHD found elsewhere. The work to date in this area has focused on women and evidence of chronic GVHD effects specific to male genital tissue or sexual functioning has been very limited.

When addressing sexual dysfunction in research or clinical care, it is important to consider contributions from biological effects on psychosocial factors. For example, low levels of testosterone (in both males and females) and years of high dose corticosteroid treatments for chronic GVHD are associated with decreased sexual desire and depressed mood. ${ }^{5,30}$ Calcineurin inhibitors or interferon treatments can affect cognitive function and mood. 31 Fatigue related to cancer and its treatment is likely to impact sex drive if it has other functional impacts. ${ }^{22,32}$ Hypothyroidism, diabetes, cardiovascular health problems and significant loss of muscle mass are all frequent after HSCT and can contribute to sexual performance problems and loss of libido. Depression and anti-depressant use, along with insomnia are known risk factors for sexual dysfunction in the general population and occur widely in transplant recipients. Thus a full medical exam is needed for HSCT survivors who report sexual dysfunction.

\section{Psychological Factors Contributing to Sexual Dysfunction}

As noted above, common symptoms after HSCT have both physiological and psychological components. Consequently, separation of these factors is somewhat artificial. Figure 1 contains a conceptual model of sexual dysfunction that includes physiological and psychological aspects. Fatigue, depression, insomnia, body changes, even pain or other physical discomforts may have biologic roots, but they also have cognitive and emotional consequences that can actively contribute to inhibiting sexual activity or responsiveness. If one barely has the energy to maintain mandatory daily activities to promote health, it can be hard to imagine saving time and energy for sex. For survivors of HSCT this is a common experience in the months after treatment. In addition, appearance changes in hair loss, muscle loss, skin rashes, skin sensitivity or dryness, scars and weight changes influence body image which in turn contributes to sexual self-consciousness. ${ }^{30,32-33}$ Fear of pain or discomfort, and even fear of failing to become aroused can become barriers to trying again for both survivors and their partners. Another barrier to return to sexual activity is the expectation that responsiveness should return to as it was before diagnosis. Lack of communication about what has changed, what feels good or not, and insecurities about appearance can inhibit couple's attempts at intercourse. These worries and lack of communicating concerns are often also reflected in reduced intimacy, since emotional intimacy and physical expressions of closeness for many couples are seen as precursors to intercourse. Patterns set in the months after returning home can turn into habits that continue for many years. 


\section{Assessment of Sexual Functioning}

To be able to confidently measure a construct, it is important to have measures that are well validated within the population being tested. The timing of assessments also becomes important as assessing sexual functioning before treatment ${ }^{32}$ allows evaluation of changes from an individual or couple's norms. Since sexual function varies so greatly across the population even within the United States, 34 individuals' norms constitute a better reference than population averages. In a study with gynecologic cancers, prior sexual functioning predicts $24 \%$ of the variance in sexual outcomes. ${ }^{35}$ After HSCT our data indicate that pretransplant sexual function predicts $19 \%$ of the variance in sexual function after 5 years, whereas 1 year sexual function predicts $36 \%$ of the variance after 5 years. ${ }^{4}$ Thus baseline and 1 year function are strong indicators of how a survivor's function will be long term for both males and females. These results also provide evidence that intervention needs to be timed to intercede if possible before 1 year after transplant. In a one year longitudinal study of sexual functioning of HSCT patients who had received high dose chemotherapy as part of their conditioning regimen, just under half of the patients reported sexual dysfunction prior to treatment. ${ }^{36}$ This finding has been supported in another study of male HSCT survivors. ${ }^{21}$ To decrease potential hesitation to raise questions or discuss sexual problems, routine assessment of sexual function by designated health care providers needs to be provided to all patients. ${ }^{9,22}$ Reluctance to engage in these discussions is often as great on the part of health care professionals as for patients, in part because providers do not see themselves as knowledgeable and able to treat the problems that patients raise. ${ }^{37-39}$ Having a standard assessment tool can decrease these barriers and give survivors and their health care providers a way to start a conversation about sexuality. This standardized measurement then becomes a reference tool for explaining both problems and progress. Thus assessment not only provides a reference marker for change but also the terminology that facilitates clinical communications. ${ }^{40}$

Recent reviews of sexuality after cancer $40-41$ indicate a need for further research into assessing sexual function. A limited number of tools have been developed for or tested with cancer patients and survivors. Those that do exist have focused on gynecological cancer $42-$ 43 and erectile dysfunction after prostate cancer. ${ }^{44-45}$ Several broad quality of life measures contain sexual functioning subscales but may be limited to one-to-three questions and not have been tested with long term cancer survivors in mind. Thus, there has been a need to devise a measure targeted to HSCT survivors for their specific needs and to do rigorous psychometric testing of sexual function measures in this population.

To meet this need, we tested the Sexual Functioning Questionnaire (SFQ) in a sample of 400 cancer survivors and their matched non-cancer controls who were of the same gender, ethnicity, and within 5 years of age of the cancer survivors. ${ }^{7}$ The questions were based on the Brief Sexual Functioning for Women (BISF-W). ${ }^{46}$ The initial form of the SFQ was tested with 200 HSCT recipients before and after their treatment. The instrument was revised to delete items that did not load on any factor and to add items that participants had written in the open-ended questions. In its final form the SFQ is a gender-specific measure with 30 items. It has 9 subscales and 2 overall scores (overall SFQ score and SFQ Treatment Impact). The 9 subscales correspond to the sexual response cycle plus specific sexual behaviors or difficulties: interest, desire, arousal, orgasm, satisfaction, masturbation, relationship, activity, and problems.

The SFQ asks about sexual practices in the past month. The measure does not depend on the participant having a partner, the sexual orientation of the participant, or the medical condition of the respondent. However, there is a Treatment Impact Scale that can be scored separately so that the impact of specific treatments on sexuality can be assessed. Principal components analyses were conducted separately for men and women. No item factor loading differences were found by gender, therefore for the final factor analysis both males and females were 
combined. Factor loadings for each item were above 0.5 . Reliabilities were above 0.8 for each of the subscales and for the total score. There was also high test-retest reliability when comparing pre- and post-transplant. The SFQ had very good psychometric properties as evidenced by the reliabilities and validation confirmed with content, construct, and criterion validity. Discriminant validity was also established with the ability of the measure to distinguish between survivors and controls.

With the National Institutes of Health and the Patient-Reported Outcomes Measurement System (PROMIS) Network, ${ }^{47}$ there is a unique opportunity to have an item bank specifically for sexual functioning. Measures for fatigue, distress, pain, social function, physical function have already been developed through the PROMIS initiative. A sexual function item bank will be available in the near future for use. An additional need in this area is to validate a measure for same sex couples as the work to date has been primarily with heterosexual couples. ${ }^{41}$

\section{Evidence on Sexuality after HSCT}

Lower sexual activity and satisfaction after HSCT in comparison to the time before transplantation or relative to the general population is a consistent finding across time points after HSCT, and across ages at time of transplantation, in both prospective longitudinal and cohort comparison studies. ${ }^{5,8,22,33,48-53}$ Numerous cross-sectional studies have documented declines in sexual satisfaction and functioning of HSCT survivors. $3,5,33$ Survivors of both genders report a loss of sexual desire. ${ }^{54}$ Nonetheless reported rates of sexual satisfaction vary quite widely perhaps because of different measures used or adequacy of sampling. As few as $22 \%$ of participants have reported sexual dissatisfaction, 33 while in most studies half or more of the participants report dissatisfaction. ${ }^{53,55} \mathrm{Few}$ studies have continued to followed HCST survivors long term to assess their sexual functioning after full recovery. However, decrements in sexual functioning have been found in long-term survivors past 5 years after treatment. ${ }^{4}$

Since differences, both in problem rates and satisfaction, are marked between males and females it is necessary to consider effects on these survivors separately. Before HSCT 42 percent of females and 14 percent of males report one or more sexual problems, compared with 17 to 35 percent of the general population of females and up to 19 percent of males. ${ }^{5}$ By three years after HSCT, the prevalence of problems increases to 80 percent of females and 29 percent of males. Also by 3 years post-transplant, a majority of women report difficulties with lubrication and desire, whereas the most prevalent problems for men include obtaining and maintaining erections and desire. $5,25,55-57$

In a 5 year prospective, longitudinal examination of sexual functioning, almost $20 \%$ of women between 6 months and 5 years reported a lack of interest whereas lack of interest for men decreased from $14 \%$ at 6 months after treatment to $6 \%$ after 5 years. ${ }^{4}$ As indicated by our research (Figure 2), men and women who had relapse-free survival were able to recover their sexual activity to their pre-treatment levels but remained lower than controls at five years. ${ }^{4}$ Women continued to have lower rates of sexual activity than men across time, and at all times over $40 \%$ of female HSCT survivors were sexually inactive. A similar picture emerges for the quality of overall sexual functioning, as can be seen in Figure 3. In general, women report more problems than men do, ${ }^{22,30}$ and men report higher levels of sexual satisfaction than women. ${ }^{26}$ However, both males and females generally note that their difficulties are not in their sexual relationships but rather with desire and specific sexual problems.

Due to the high levels of ovarian failure in women who had HSCT, it is common for women to experience menopausal symptoms. For example, vaginal dryness is highly prevalent and this can make intercourse uncomfortable. ${ }^{5,10,28,55}$ Women also report pain 58 during 
intercourse and, less often, bleeding after intercourse. ${ }^{28}$ Another problem for women that seems to increase with time is the ability to achieve an orgasm. 5

These findings to date with HSCT survivors highlight that, while physical and emotional functioning may return to normal with the passage of time for most survivors, ${ }^{3,59}$ sexual functioning does not follow a similar trajectory. ${ }^{4,57}$ A finding that highlights the importance of assessing sexual functioning early after treatment is that, for women in particular, if sexual activity has not returned by 1 year, these problems can persist for 5 years and possibly indefinitely. ${ }^{5}$ Our research also highlights that if women are not taking HRT by 1 year, their sexual problems are more likely to continue.

\section{Risk Factors for Sexual Dysfunction after HSCT}

Other than gender, few clear risk factors for poorer sexual function have been identified. In part, this is because these difficulties are so prevalent and most treatments have some impact on sexual problems. Men and women are at risk for enduring sexual problems, regardless of the type of transplant received. ${ }^{6}$ Age is also a variable to consider, as younger women and those who are premenopausal before transplant report more problems with lubrication and other menopausal symptoms. ${ }^{5}$ Other risk factors for women include initiation of hormone therapy after one year post-transplantation, being premenopausal before transplant and chronic GVHD. For men risk factors include older age, chronic GVHD and psychological function prior to HSCT. $5,7,22$. Prospective cohort studies indicate that hormone therapy with oral estrogen improves or prevents more serious decline in sexual function in women after HSCT, but does not eliminate problems. $5,19,26$

\section{Related Issues: Sexual Relationships and Other Underlying Issues}

Clearly, most sex does not happen in a relationship vacuum and most people prefer to have sex with another person. A partner's needs and responses are relevant in determining both participants' sexual satisfaction. Numerous relationship issues after HSCT can disrupt the psychological responsiveness of one or both partners.

Preoccupation with health-focused tasks or worry by a partner, or a change in relationship balance, will potentially influence the couple's intimacy and, in turn, their sexual interest and responsiveness to sexual signals or approaches. Two aspects of this balance that are predictable after HSCT include the issue of infertility and the changes in roles. Any couple or individual who does not yet have children at the time of transplantation can be expected to have concerns about how they will manage infertility ${ }^{60}$ Our research has documented that these concerns do not resolve with time and take active discussion and problem solving by couples. Role changes caused by a patient's focus on survival and the need for a spouse to move into a caregiving position in the relationship can inhibit return to sexual activity. In addition, survivors and spouses may engage in protective buffering 61 and not express sexual interests or concerns about infertility issues for fear of upsetting or burdening their partner.

For single individuals the issues can be somewhat different than for those who are in a stable couple relationship. It can be difficult to explain to a new partner, or partners, the effects of chemotherapy and/or chronic GVHD on genital tissues and sexual responsiveness. This is especially true for young women who may be prematurely postmenopausal or young men whose erections are not as firm as expected. Guidance in raising these issues with new dating situations can be helpful for young adults especially, who may avoid relationships out of fear of not meeting their partner's expectations for sexual behavior. 


\section{Medical Treatment Options}

Medical treatments exist for the treatment of sexual dysfunction. However, health care professionals are usually untrained to have the relevant discussions needed to appropriately prescribe care. ${ }^{38}$ Training of these health care providers is needed to improve outcomes in sexual function for HSCT and other cancer survivors. Patients need careful assessment and discussion of their sexual functioning prior to the initiation of chemotherapy, not only when problems are entrenched. ${ }^{23}$ This can prepare patients and partners for the sexual changes that are common and can initiate a discussion of potential treatment options. Further, it alerts patients and partners of the need to plan for and act on their return to sexual activity before years pass. For both men and women, randomized controlled trials need to be conducted to determine which biologic treatments are efficacious and safe.

If a woman is premenopausal, discussion of hormone therapy options is needed so that these can begin as soon after transplant as medically safe. The risks and benefits of hormone therapy need to be discussed, along with a plan for when hormone therapy would be discontinued and under what conditions. In a non-randomized study of younger women who did versus did not take hormone therapy, taking hormones did not effect chronic GVHD in allogeneic survivors. 19 Nonetheless hormone therapy would not be an option for women with elevated risks for hormone-sensitive tumors or those who have chronic GVHD of the liver. ${ }^{5,12}$ Hormone therapy will sometimes restore ovarian function 62 and not just alleviate symptoms. A study that assessed the relationship between hormones and sexual functioning found that women still experienced sexual dissatisfaction while taking estrogen therapy. ${ }^{26}$ This could be due to the reduced effectiveness of the hormones because of decreased absorption in the intestinal tract. 12 Testosterone therapy has been thought to increase sexual libido, but was not found to do so in a group of female cancer survivors who were not also on estrogen therapy. ${ }^{63}$ Randomized controlled trials have yet to be conducted on the efficacy of hormones for sexual dysfunction in women after HSCT, and more research is needed on the risk-benefit ratio of hormone therapy to be able to recommend this option with appropriate safety and efficacy qualifications. Still the abnormal and premature cessation of endogenous hormones for a young adult female is equally untested for consequences, safety and efficacy. In short, a balance of empirical testing of hormones and thoughtful weighting of risks and benefits for the individual is the best recommendation possible at this point.

Women may find topical estrogen to be helpful in the treatment of vaginal dryness or constriction, and for women who have vaginal or vulva chronic GVHD, topical cyclosporine may be another treatment to consider. ${ }^{28}$ Some women use vaginal dilators to reduce constriction and sensitivity to penile penetration. In more extreme cases, women with vaginal stenosis may need surgery. ${ }^{28-29}$ However, the use of estrogen creams or dilators may obviate the need for surgery to correct stenosis. The research in this area has small sample sizes and, possibly for that reason, data are conflicting. One study has described the use of topical estrogen as helpful in relieving chronic GVHD symptoms, ${ }^{28}$ and another found it ineffective. ${ }^{29}$

Male sexual problems center on libido and erectile dysfunction. ${ }^{56}$ Results from a small case series of eight patients six months after HSCT suggested that testosterone injections and sildenafil one to two times per week improved sexual performance for men with erectile dysfunction, low libido and ejaculatory disorders. ${ }^{56}$ However, other data indicate that most males recover testosterone levels and sexual function between six months and one year after transplantation. ${ }^{64}$ Thus without controlled clinical trials, it is unclear whether sexual function in the treated men would have recovered without treatment so caution is needed when interpreting the results and in applying them in practice. If medications do not work, men can consider external vacuum devices or penile implants, but very few elect mechanical solutions to erectile problems. ${ }^{65-66}$ 
A drug that has shown promise in treating ED in men and lack of arousal in women is a class of drugs called melanocortins. ${ }^{67}$ Bremelanotide, a type of drug in this class, has been used in healthy men and was found to be effective in treating ED. This drug may have a safer profile than that of sildenafil because melanocortins can be used in conjunction with nitrates, which is not the case for sildenafil and other drugs like it. In women, bremelanotide has been associated with increases in self-reported arousal. More research needs to be done with melanocortins and to also test the drug in a group of cancer survivors as the samples to date have used healthy people.

As noted earlier, sexuality involves both biologic and psychological responses. While medical factors and medications may inhibit sexual response, the cognitive and psychological responses to these biologic factors will have a major impact on sexual satisfaction. As a major component of this psychological response, relationship quality and the response of a partner to the physiologic changes after transplant will positively or negatively affect sexual functioning. 22,54

\section{Behavioral Treatment Options}

A majority of sexual changes after HSCT are managed with behavioral strategies and, for women, topical agents or devices rather than medical treatment. A combination of approaches is likely to be most effective, utilizing education, hormone evaluation, hormone therapy where indicated, topical or behavioral strategies, and couples intervention. No study has tested this combination of therapies to address sexual dysfunction after HSCT.

A few interventions that are likely applicable to HSCT survivors have been tested with other cancer populations. Robinson and colleagues 68 used a group intervention for women who were diagnosed with gynecological cancer and were treated with radiation therapy. Women were randomized to one of two groups: an intervention that included education about how to use lubricants and vaginal dilators or a control group. The intervention group consisted of two 1.5 hour group sessions. Women were informed about sexuality and cancer, encouraged to talk about their fears, and educated about the use of dilators and lubricants. Women in the control condition met with a counselor and were given a book on sexuality. Women of all ages reported a decrease in the fear of sexual activity and women under the age of 50 in the experimental group were more adherent to the recommendations regarding the use of lubricants and dilators than were older women. This trial is a promising start in testing strategies to teach women how return to sexuality after treatment but also demonstrates that compliance is an issue with behavioral treatment recommendations. Behavioral treatments after breast cancer have also demonstrated improvements in sexual functioning. Scott and colleagues 69 tested a couplebased intervention for patients diagnosed with either early stage breast or gynecological cancers. The couple-based intervention was more effective at improving sexual adjustment than an individually-based intervention. A major strength of this study was the use of pre- and post-test measurements, along with a 1 year follow-up. Although the findings are promising, these interventions need to be tested with HSCT survivors.

While traditional sex therapy such as sensate focus treatment ${ }^{70}$ and medications are available to treat sexual dysfunction, there are other important issues to consider. After cancer and HSCT, in our clinical practice we find that a communication and intimacy-based approach is remarkably effective for many couples in facilitating return to satisfying sexual activity. In addition to addressing fears and overcoming avoidance, we encourage gradual re-introduction of sexual activity beginning with scheduling of time for 'dating' and intimacy without intercourse. Even one or two couples counseling sessions focused on communication around appearance, fears or barriers, and changes in sensation can facilitate readiness to engage in intimacy and return to sexual practice. Since vaginal dryness is so common, we recommend 
lubricants for all women after HSCT until experience informs them whether continued use of lubricants is needed. When avoidance, fear or negative experiences have added to sexual problems, we urge women alone or couples to try vibrators and dilators until they are comfortable with their physical responses. Helping couples to decide on hand signals or other brief communication cues can facilitate their feeling safe to try sexual activity after a long period of abstinence and numerous psychological and physical adjustments.

Depression or fear, fatigue, loss of muscle mass, antidepressant use or other medications that impact libido and arousal, as well as relationship conflict are just a few factors that need to be assessed when considering behavioral approaches to sexual dysfunction. ${ }^{54}$ When deciding on treatment strategies, it is important to consider the multiple pathways to sexual dysfunction along with the many ways that people can increase their sexual satisfaction beyond traditional intercourse. For most people this involves a gradual return to intercourse with a partner, but not infrequently, full erections, orgasm or sexual responsiveness are not achieved at the same level as before diagnosis. Nonetheless many survivors find satisfaction from renewed intimacy and sexual function that is rewarding if not fully at the level they would wish for.

\section{Deficits in Research on Understanding and Treating Sexual Dysfunction after HSCT}

While we know from survey and longitudinal research that sexuality is a major concern for many HSCT survivors, there are gaps in the research that need to be filled. Much of the research has been conducted with white, heterosexual, middle or upper economic class couples. Little is known about the sexual functioning, needs or concerns of people who are not in committed relationships, have cultural or other differences from the usual research samples, or are in same sex relationships. In addition, little is known about HSCT survivors who are sexually inactive for many years after treatment. We do not yet know much about the sexual outcomes of survivors who received reduced intensity chemotherapies followed by HSCT. While descriptive studies have been recently published, mechanism and treatment studies are severely lacking. The need for studies of treatment in this area cannot be overstated given the prevalence of problems, the conflicting or uncertain data from those outcomes that are published, and the questions of safety for some of the hormonal treatments frequently described.

\section{Conclusions}

As more people survive cancer and its associated treatments, it becomes imperative to monitor survivors for long term and late effects. This is especially the case for sexual function after HSCT. These generally young adult survivors have typically undergone high dose treatments to cure their malignancies, and sexual dysfunction is one of the most prevalent long term complications of treatment. Survivors and their partners should be assessed for their sexual functioning prior to treatment so that any changes may be tracked over time and the appropriate treatment recommendations can be made. Although medical and behavioral treatments similar to those used in other populations who experience dramatic changes in sexual response can be used, the safety and efficacy of these treatments in the long term HSCT survivor population remains to be tested and documented.

\section{Acknowledgments}

We thank Allison Stover for her assistance with manuscript preparation.

Acknowledgment of Funding Sources: National Cancer Institute grants CA 112631, CA78990, CA 63030 and Lance Armstrong Foundation TE 4198. 


\section{References List}

1. Socie G, Stone JV, Wingard JR, Weisdorf D, Henslee-Downey PJ, Bredeson C, et al. Long-term survival and late deaths after allogeneic bone marrow transplantation: late effects working committee of the international bone marrow transplant registry. NEJM 1999;341:14-21. [PubMed: 10387937]

2. Syrjala, KL.; Martin, P.; Deeg, J.; Boeckh, M. Medical and psychosocial issues in transplant survivors. In: Chang, AE.; Ganz, PA.; Hayes, DF.; Kinsella, T.; Pass, HI.; Schiller, JH., et al., editors. Oncology: An Evidence-Based Approach. New York, NY: Springer Science + Business Media, Inc; 2006. p. 1902-1928.

3. Syrjala KL, Langer SL, Abrams JR, Storer BE, Martin PJ. Late effects of hematopoietic cell transplantation among 10-year adult survivors compared with case-matched controls. Journal of Clinical Oncology 2005;23:6596-6606. [PubMed: 16170167]

4. Syrjala KL, Kurland BF, Abrams JR, Sanders JE, Heiman JR. Sexual function changes during the 5 years after high-dose treatment and hematopoietic cell transplantation for malignancy, with casematched controls at 5 years. Blood 2008;111:989-996. [PubMed: 17878404]

5. Syrjala KL, Roth-Roemer SL, Abrams JR, Scanlan JM, Chapko MK, Visser S, et al. Prevalence and predictors of sexual dysfunction in long-term survivors of marrow transplantation. Journal of Clinical Oncology 1998;16:3148-3157. [PubMed: 9738587]

6. Lee SJ, Fairclough D, Parsons SK, Soiffer RJ, Fisher DC, Schlossman RL, et al. Recovery after stemcell transplantation for hematologic diseases. Journal of Clinical Oncology 2001;19:242-252.

[PubMed: 11134219]

7. Syrjala KL, Schroeder TC, Abrams JR, Atkins TZ, Brown WS, Sanders JE, et al. Sexual function measurement and outcomes in cancer survivors and matched controls. Journal of Sex Research 2000;37:213-225.

8. Andrykowski MA, Bishop MM, Hahn EA, Cella DF, Beaumont JL, Brady MJ, et al. Long-term healthrelated quality of life, growth, and spiritual well-being after hematopoietic stem-cell transplantation. Journal of Clinical Oncology 2005;23:599-608. [PubMed: 15659507]

9. Schover, LR.; Schain, WS.; Montague, DK. Sexual problems of patients with cancer. In: DeVita, V.; Hellman, S.; Rosenberg, SA., editors. Principles and Practice of Oncology. Vol. 3rd Edition ed.. Philadelphia, Pensylvaina: J.B. Lippincott; 1989. p. 2206-2225.

10. Cust MP, Whitehead MI, Powles R, Hunter M, Milliken S. Consequences and treatment of ovarian failure after total body irradiation for leukemia. British Medical Journal 1989;299:1494-1497. [PubMed: 2514860]

11. Lee SJ, Schover LR, Partridge AH, Patrizio P, Wallace WH, Hagerty K, et al. American Society of Clinical Oncology recommendations on fertility preservation in cancer patients. Journal of Clinical Oncology 2006;24:2917-2931. [PubMed: 16651642]

12. Tauchmanova L, Selleri C, Rosa GD, Pagano L, Orio F, Lombardi G, et al. High prevalence of endocrine dysfunction in long-term survivors after allogeneic bone marrow transplantation for hematologic diseases. Cancer 2002;95:1076-1084. [PubMed: 12209694]

13. Apperley JF, Reddy N. Mechanism and management of treatment-related gonadal failure in recipients of high dose chemoradiotherapy (Review). Blood Reviews 1995;9:93-116. [PubMed: 7580395]

14. Sanders JE, Buckner CD, Leonard JM, Sullivan KM, et al. Late effects on gonadal function of cyclophosphamide, total-body irradiation, and marrow transplantation. Transplantation 1983;36:252-255. [PubMed: 6412404]

15. Kauppila M, Koskinen P, Irjala K, Remes K, Viikari J. Long-term effects of allogeneic bone marrow transplantation [BMT] on pituitary, gonad, thyroid and adrenal function in adults. Bone Marrow Transplantation 1998;22:331-337. [PubMed: 9722067]

16. Schubert MA, Sullivan KM, Schubert MM, Nims J, Hansen M, Sanders JE, et al. Gynecological abnormalities following allogeneic bone marrow transplantation. Bone Marrow Transplantation 1990;5:425-430. [PubMed: 2369683]

17. Chatterjee R, Kottaridis PD, McGarrigle HH, Linch DC. Management of erectile dysfunction by combination therapy with testosterone and sildenafil in recipients of high-dose therapy for haematological malignancies. Bone Marrow Transplantation 2002;29:607-610. [PubMed: 11979311] 
18. Heaton, RK.; Grant, I.; Matthews, CG. Comprehensive Norms For an Expanded Halstead-Reitan Battery. Odesa, FL: Psychological Assessment Resources, Inc.; 1992.

19. Balleari E, Garre S, van Lint MT, Spinelli S, Chiodi S, Repetto E, et al. Hormone replacement therapy and chronic graft-versus-host disease activity in women treated with bone marrow transplantation for hematologic malignancies. Annals of the New York Academy of Sciences 2002;966:187-192. [PubMed: 12114271]

20. Chatterjee R, Kottaridis PD. Treatment of gonadal damage in recipients of allogeneic or autologous transplantation for haematological malignancies. Bone Marrow Transplantation 2002;30:629-635. [PubMed: 12420200]

21. Monti M, Rosti G, De Giorgi U, Cavallari G, Severini G, Giovanis P, et al. Sexual functions after high-dose chemotherapy in survivors of germ cell tumors. Bone Marrow Transplantation 2003;32:933-939. [PubMed: 14561995]

22. Watson M, Wheatley K, Harrison GA, Zittoun R, Gray RG, Goldstone AH, et al. Severe adverse impact on sexual functioning and fertility of bone marrow transplantation, either allogeneic or autologous, compared with consolidation chemotherapy alone: analysis of the MRC AML 10 trial. Cancer 1999;86:1231-1239. [PubMed: 10506708]

23. Socie G, Salooja N, Cohen A, Rovelli A, Carreras E, Locasciulli A, et al. Nonmalignant late effects after allogeneic stem cell transplantation. Blood 2003;101:3373-3385. [PubMed: 12511420]

24. Shadiack AM, Sharma SD, Earle DC, Spana C, Hallam TJ. Melanocortins in the treatment of male and female sexual dysfunction (Review). Current Topics in Medicinal Chemistry 2007;7:1137-1144. [PubMed: 17584134]

25. Baruch J, Benjamin S, Treleaven J, Wilcox AH, Barron JL, Powles R. Male sexual function following bone marrow transplantation. Bone Marrow Transplantation 1991;7:52. [PubMed: 1878717]

26. Heinonen H, Volin L, Uutela A, Zevon M, Barrick C, Ruutu T. Gender-associated differences in the quality of life after allogeneic BMT. Bone Marrow Transplantation 2001;28:503-509. [PubMed: 11593325]

27. Hayes EC, Rock JA. Treatment of vaginal agglutination associated with chronic graft-versus-host disease. Fertility \& Sterility 2002;78:1125-1126. [PubMed: 12414005]

28. Spiryda LB, Laufer MR, Soiffer RJ, Antin JA. Graft-versus-host disease of the vulva and/or vagina: diagnosis and treatment. Biology of Blood \& Marrow Transplantation 2003;9:760-765. [PubMed: 14677115]

29. Spinelli S, Chiodi S, Costantini S, van Lint MT, Raiola AM, Ravera GB, et al. Female genital tract graft-versus-host disease following allogeneic bone marrow transplantation. Haematologica 2003;88:1163-1168. [PubMed: 14555313]

30. Humphreys CT, Tallman B, Altmaier EM, Barnette V. Sexual functioning in patients undergoing bone marrow transplantation: a longitudinal study. Bone Marrow Transplantation 2007;39:491-496. [PubMed: 17322932]

31. Couriel D, Carpenter PA, Cutler C, Bolaños-Meade J, Treister NS, Gea-Banacloche J, et al. Ancillary therapy and supportive care of chronic graft-versus-host disease: national institutes of health consensus development project on criteria for clinical trials in chronic graft-versus-host disease: v. ancillary therapy and supportive care working group report. Biology of Blood \& Marrow Transplantation 2006;12:375-396. [PubMed: 16545722]

32. Mumma GH, Mashberg D, Lesko LM. Long-term psychosexual adjustment of acute leukemia survivors: impact of marrow transplantation versus conventional chemotherapy. General Hospital Psychiatry 1992;14:43-55. [PubMed: 1730401]

33. Wingard JR, Curbow B, Baker F, Zabora J, Paintadosi S. Sexual satisfaction in survivors of bone marrow transplantation. Bone Marrow Transplantation 1992;9:185-190. [PubMed: 1511256]

34. Laumann EO, Paik A, Rosen RC. Sexual dysfunction in the United States: prevalence and predictors. JAMA 1999;281:537-544. [PubMed: 10022110]

35. Andersen BL. Surviving cancer: the importance of sexual self-concept. Medical \& Pediatric Oncology 1999;33:15-23. [PubMed: 10401492]

36. Marks DI, Friedman SH, Carpini LD, Nezu CM, Nezu AM. A prospective study of the effects of high-dose chemotherapy and bone marrow transplantation on sexual function in the first year after transplant. Bone Marrow Transplantation 1997;19:819-822. [PubMed: 9134175] 
37. Stead ML, Brown JM, Fallowfield L, Selby P. Lack of communication between healthcare professionals and women with ovarian cancer about sexual issues. British Journal of Cancer 2003;88:666-671. [PubMed: 12618871]

38. Vadaparampil S, Quinn G, King L, Wilson C, Nieder M. Barriers to fertility preservation among pediatric oncologists. Patient Education and Counseling 2008;72:402-410. [PubMed: 18621502]

39. Hordern AJ, Street AF. Communicating about patient sexuality and intimacy after cancer: mismatched expectations and unmet needs. Medical Journal of Australia 2007;186:224-227. [PubMed: 17391082]

40. Corona G, Jannini EA, Maggi M. Inventories for male and female sexual dysfunctions (Review). International Journal of Impotence Research 2006;18:236-250. [PubMed: 16267565]

41. Arrington R, Cofrancesco J, Wu AW. Questionnaires to measure sexual quality of life (Review). Quality of Life Research 2004;13:1643-1658. [PubMed: 15651536]

42. Jensen PT, Klee MC, Thranov I, Groenvold M. Validation of a questionnaire for self-assessment of sexual function and vaginal changes after gynaecological cancer. Psycho-Oncology 2004;13:577592. [PubMed: 15295778]

43. Bransfield D, Horiot JC, Nabid A. Development of a scale for assessing sexual function after treatment for gynecologic cancer. Journal of Psychosocial Oncology 1984;2:3-19.

44. Wei JT, Dunn RL, Litwin MS, Sandler HM, Sanda MG. Development and validation of the expanded prostate cancer index composite (EPIC) for comprehensive assessment of health-related quality of life in men with prostate cancer. Urology 2000;56:899-905. [PubMed: 11113727]

45. Litwin MS, Hays RD, Fink A, Ganz PA, Leake B, Brook RH. The UCLA Prostate Cancer Index: development, reliability, and validity of a health-related quality of life measure. Medical Care 1998;36:1002-1012. [PubMed: 9674618]

46. Taylor JF, Rosen RC, Leiblum SR. Self-report assessment of female sexual function: psychometric evaluation of the brief index of sexual functioning for women. Archives of Sexual Behavior 1994;23:627-643. [PubMed: 7872859]

47. Garcia SF, Cella D, Clauser SB, Flynn KE, Lai JS, Reeve BB, et al. Standardizing patient-reported outcomes assessment in cancer clinical trials: a patient-reported outcomes measurement information system initiative (Review). Journal of Clinical Oncology 2007;25:5106-5112. [PubMed: 17991929]

48. Bush NE, Donaldson GW, Haberman MH, Dacanay R, Sullivan KM. Conditional and unconditional estimation of multidimensional quality of life after hematopoietic stem cell transplantation: a longitudinal follow-up of 415 patients. Biology of Blood \& Marrow Transplantation 2000;6:576591. [PubMed: 11071263]

49. Zittoun R, Suciu S, Watson M, Solbu G, Muus P, Mandelli F, et al. Quality of life in patients with acute myelogenous leukemia in prolonged first complete remission after bone marrow transplantation [allogeneic or autologous] or chemotherapy: a cross - sectional study of the EORTC-GIMEMA AML 8 A trial. Bone Marrow Transplantation 1997;20:307-315. [PubMed: 9285546]

50. Chiodi S, Spinelli S, Ravera G, Petti AR, van Lint MT, Lamparelli T, et al. Quality of life in 244 recipients of allogeneic bone marrow transplantation. British Journal of Haematology 2000;110:614619. [PubMed: 10997973]

51. Howell SJ, Radford JA, Smets EM, Shalet SM. Fatigue, sexual function and mood following treatment for haematological malignancy: the impact of mild Leydig cell dysfunction. British Journal of Cancer 2000;82:789-793. [PubMed: 10732747]

52. Schimmer AD, Ali V, Stewart AK, Imrie K, Keating A. Male sexual function after autologous blood or marrow transplantation. Biology of Blood \& Marrow Transplantation 2001;7:279-283. [PubMed: 11400950]

53. Molassiotis A, van den Akker OB, Milligan DW, Boughton BJ. Gonadal function and psychosexual adjustment in male long-term survivors of bone marrow transplantation. Bone Marrow Transplantation 1995;16:253-259. [PubMed: 7581144]

54. Schover, L. Reproductive complications and sexual dysfunction in cancer survivors. In: Ganz, P., editor. Cancer survivorship: today and tomorrow. New York: Springer; 2007. p. 251-271.

55. Claessens JJ, Beerendonk CC, Schattenberg AV. Quality of life, reproduction and sexuality after stem cell transplantation with partially T-cell-depleted grafts and after conditioning with a regimen 
including total body irradiation. Bone Marrow Transplantation 2006;37:831-836. [PubMed: 16547485]

56. Chatterjee R, Kottaridis PD, McGarrigle HH, Eliahoo J, McKeag N, Mackinnon S, et al. Patterns of Leydig cell insufficiency in adult males following bone marrow transplantation for haematological malignancies. Bone Marrow Transplantation 2001;28:497-502. [PubMed: 11593324]

57. Schover LR. Sexuality and fertility after cancer. Hematology 2005:523-527. [PubMed: 16304430]

58. Winer EP, Lindley C, Hardee M, Sawyer WT, Brunatti C, Borstelmann NA, et al. Quality of life in patients surviving at least 12 months following high dose chemotherapy with autologous bone marrow support. Psycho-Oncology 1999;8:167-176. [PubMed: 10335560]

59. Syrjala KL, Langer SL, Abrams JR, Storer B, Sanders JE, Flowers MED, et al. Recovery and longterm function after hematopoietic cell transplantation for leukemia or lymphoma. JAMA 2004;291:2335-2343. [PubMed: 15150205]

60. Hammond C, Abrams JR, Syrjala KL. Fertility and risk factors for elevated infertility concern in 10year hematopoietic cell transplant survivors and case-matched controls. Journal of Clinical Oncology 2007;25:3511-3517. [PubMed: 17646668]

61. Langer SL, Rudd ME, Syrjala KL. Protective buffering and emotional desynchrony among spousal caregivers of cancer patients. Health Psychology 2007;26:635-643. [PubMed: 17845115]

62. Liu J, Malhotra R, Voltarelli J, Stracieri AB, Oliveira L, Simoes BP, et al. Ovarian recovery after stem cell transplantation. Bone Marrow Transplantation. 2008;41:275-278.

63. Barton DL, Wender DB, Sloan JA, Dalton RJ, Balcueva EP, Atherton PJ, et al. Randomized controlled trial to evaluate transdermal testosterone in female cancer survivors with decreased libido. Journal of the National Cancer Institute 2007;99:672-679. [PubMed: 17470735]

64. Kauppila M, Viikari J, Irjala K, Koskinen P, Remes K. The hypothalamus-pituitary-gonad axis and testicular function in male patients after treatment for haematological malignancies. Journal of Internal Medicine 1998;244:411-416. [PubMed: 9845857]

65. Glasgow M, Halfin V, Althausen AF. Sexual response and cancer. Ca: a Cancer Journal for Clinicians 1987;37:322-333. [PubMed: 3119166]

66. Miller DC, Wei JT, Dunn RL, Montie JE, Pimentel H, Sandler HM, et al. Use of medications or devices for erectile dysfunction among long-term prostate cancer treatment survivors: potential influence of sexual motivation and/or indifference. Urology 2006;68:166-171. [PubMed: 16844457]

67. Schover LR. Premature ovarian failure and its consequences: vasomotor symptoms, sexuality, and fertility (Review). Journal of Clinical Oncology 2008;26:753-758. [PubMed: 18258983]

68. Robinson JW, Faris PD, Scott CB. Psychoeducational group increases vaginal dilation for younger women and reduces sexual fears for women of all ages with gynecological carcinoma treated with radiotherapy. International Journal of Radiation Oncology, Biology, Physics 1999;44:497-506.

69. Scott JL, Halford WK, Ward BG. United we stand? The effects of a couple-coping intervention on adjustment to early stage breast or gynecological cancer. Journal of Consulting \& Clinical Psychology 2004;72:1122-1135. [PubMed: 15612858]

70. Masters, WH.; Johnson, VE. Human Sexual Response. Boston, MA: Little, Brown; 1966. 


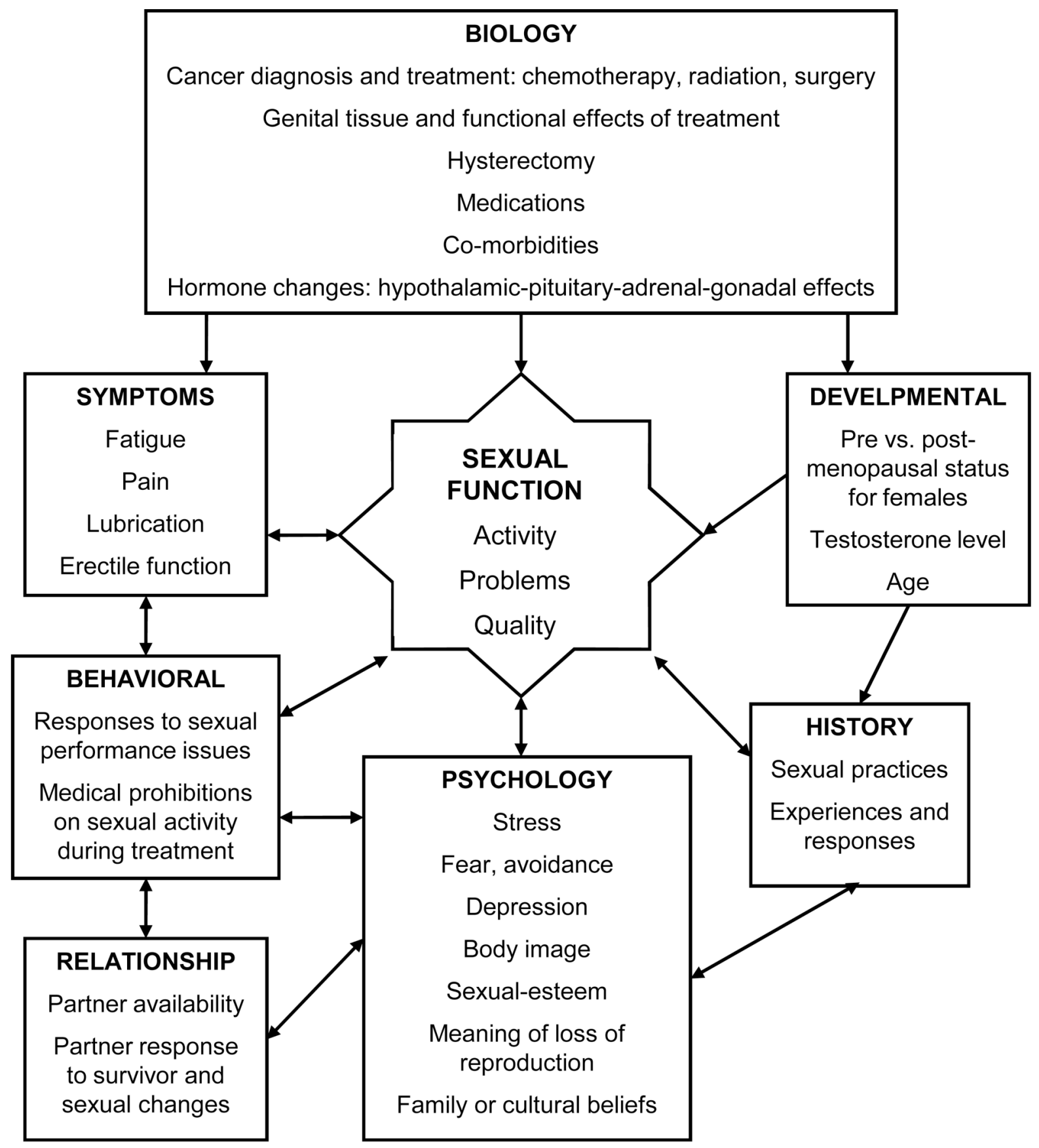

Figure 1. Conceptual model of sexual dysfunction causes and effects in cancer survivors 


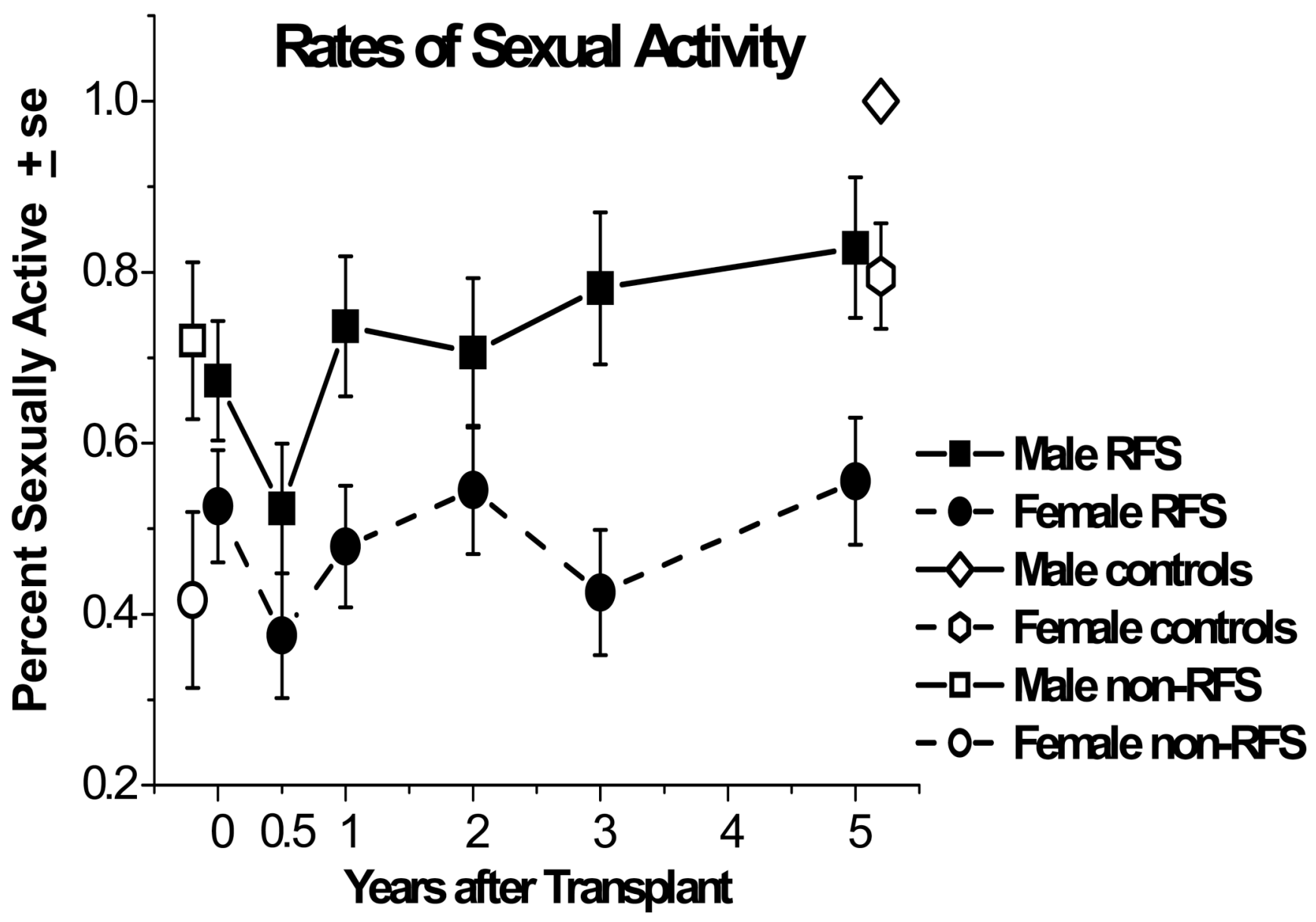

Figure 2. Percent of males and females who were sexually active, among responding relapse-freesurvivors (RFS) from before transplant $(\mathrm{N}=109)$ to 5 years after transplant $(\mathrm{N}=80)$

Rates are also graphed for non-RFS patients before transplant $(\mathrm{N}=49)$ and controls at 5 years $(\mathrm{N}=77)$. Both males and females declined in rates of being sexually active from pretransplant to 6 months $(P=.05)$. On average, males improved compared to 6 month levels by 1 year $(P=$. $02)$; females improved by 2 years $(P=.03)$, but both remained below their respective controls at 5 years. 


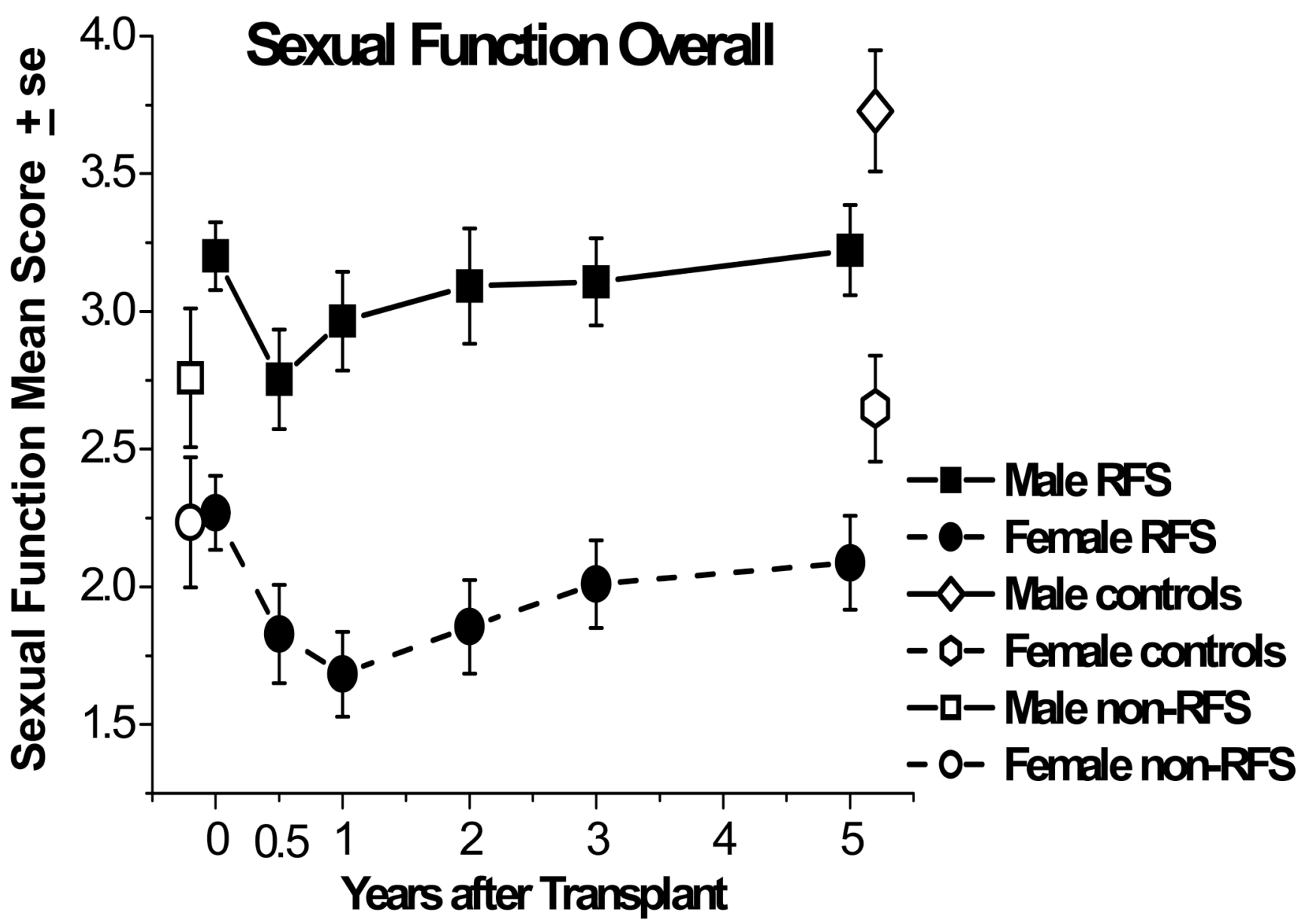

Figure 3. Sexual function means for responding male and female relapse-free-survivors (RFS) from before transplant $(\mathrm{N}=109)$ to 5 years after transplant $(\mathrm{N}=80)$, measured on the same scale, though with different problem items content

Means are also graphed for non-RFS patients before transplant $(\mathrm{N}=49)$ and controls at 5 years $(\mathrm{N}=77)$. Both males and females declined in average sexual function from pretransplant to 6 months $(P<.01)$. Females did not improve from 6-month posttransplant levels by 5 years $(P=$. $17)$ and remained below matched controls $(P=.03)$. Males improved by 2 years $(P=.02)$, but remained below their respective controls at 5 years $(P=.01)$. 